Perdok, H., Jans, S., Verhoeven, C., Dillen C., Batenburg, R., Mol, B.W., Schellevis, F., Jonge, An de. Opinions of professionals about integrating midwife- and obstetrician-led care in The Netherlands. Midwifery: 2016, 37(6), 9-18

\begin{tabular}{|l|l|}
$\begin{array}{l}\text { Postprint } \\
\text { Version }\end{array}$ & 1.0 \\
\hline Journal website & http://linkinghub.elsevier.com/retrieve/pii/S0266-6138(16)30015-8 \\
\hline Pubmed link & http://www.ncbi.nlm.nih.gov/pubmed/27217232 \\
\hline DOI & 10.1016/j.midw.2016.03.011 \\
\hline
\end{tabular}

This is a NIVEL certified Post Print, more info at http://www.nivel.eu

\title{
Opinions of professionals about integrating midwife- and obstetrician-led care in The Netherlands
}

\author{
HILDE PERDOK,RM,MSC(JUNIORMIDWIFERESEARCHER $)^{\mathrm{A}, \mathrm{N}}$, SUZE \\ JANS,RM,PHD(MIDWIFERESEARCHER,POLICYADVISOR) $)^{\mathrm{B}, \mathrm{H}}$, CORINE \\ VERHOEVEN,RM,PHD(SENIORMIDWIFERESEARCHER) ${ }^{A, C}$, \\ JEROENVANDILLEN,MD,PHD(CONSULTANTOBSTETRICIAN $)^{\mathrm{D}}$, \\ RONALDBATENBURG,PHD(PROGRAMLEADER $)^{\mathrm{E}}$, BEN \\ WILLEMMOL,MD,PHD(PROFESSOROFOBSTETRICSANDGYNAECOLOGY) $)^{\mathrm{F}}$, \\ FrANÇOISSCHELLEVIS,MD,PHD(PROFESSOROFGENERALPRACTICE) ${ }^{\mathrm{E}, \mathrm{G}}$, ANK \\ DEJONGE,RM,PHD(SENIORMIDWIFERESEARCHER)
}

a a Department ofMidwiferyScience,AVAGandtheEMGOp Institute

forHealthandCareResearch,VUUniversityMedicalCentre,Amsterdam,TheNetherlands

b Department ofCommunityGeneticsattheEMGOp Institute

forHealthandCareResearch,VUUniversityMedicalCentre,Amsterdam, TheNetherlands

c Maxima MedicalCentre, Veldhoven, TheNetherlands

d Department of

ObstetricsandGynaecology,RadboudUniversityMedicalCentre(Radboudumc)Nijmegen, The

Netherlands

e Netherlands InstituteforHealthServicesResearch(NIVEL), TheNetherlands

fRobinsonInstitute,SchoolofPaediatricsandReproductiveHealth,UniversityofAdelaide,Adelaid

e,Australia

g DepartmentofGeneralPractice\&ElderlyCareMedicine,EMGOp

InstituteforHealthandCareResearch,VUUniversityMedicalCentre,Amsterdam, TheNetherlan ds

h RoyalDutchOrganisationofMidwives, Utrecht, TheNetherlands

\begin{abstract}
Objective

the current division between midwife-led and obstetrician-led care creates fragmentation in maternity care in the Netherlands. This study aims to gain insight into the level of consensus among maternity care professionals about facilitators and barriers related to integration of midwife-led and obstetrician-led care. Integration could result in more personal continuity of care for women who are referred during labour. This may lead to better birth experiences, fewer interventions and better outcomes for both mother and infant.

Design
\end{abstract}


Perdok, H., Jans, S., Verhoeven, C., Dillen C., Batenburg, R., Mol, B.W., Schellevis, F., Jonge, An de. Opinions of professionals about integrating midwife- and obstetrician-led care in The Netherlands. Midwifery: 2016, 37(6), 9-18

a descriptive study using a questionnaire survey of 300 primary care midwives, 100 clinical midwives and 942 obstetricians.

Setting

the Netherlands in 2013.

Participants

131 (response 44\%) primary care midwives, 51 (response 51\%) clinical midwives and 242 (response $25 \%$ ) obstetricians completed the questionnaire.

Findings

there was consensus about the clinical midwife caring for labouring women at moderate risk of complications. Although primary care midwives themselves were willing to expand their tasks there was no consensus among respondents on the tasks and responsibilities of the primary care midwife. Professionals agreed on the importance of good collaboration between professionals who should work together as a team. Respondents also agreed that there are conflicting interests related to the payment structure, which are a potential barrier for integrating maternity care.

Key conclusions

this study shows that professionals are positive regarding an integrated maternity care system but primary care midwives, clinical midwives and obstetricians have different opinions about the specifications and implementation of this system.

Implication for practice

our findings are in accordance with earlier research, showing that it is too early to design a blueprint for an integrated maternity care model in the Netherlands. To bring about change in the maternity care system, an implementation strategy should be chosen that accounts for differences in interests and opinions between professionals.

\section{INTRODUCTION}

A division between midwife-led and obstetrician-led care traditionally characterizes maternity care in the Netherlands, but pregnant women, professionals and other stakeholders are increasingly questioning this division. One of the consequences of this division is that after transfer from midwife-led care to obstetrician-led care, the primary care midwife is no longer involved which results in discontinuity of caregiver (de Jonge et al., 2014 and Wiegers, 2009) potentially leading to loss of important obstetric information (Evers et al., 2010) with a potential impact on quality and safety of care. In this study, "integration of care" is defined as closer collaboration between midwives and obstetricians. Integration of midwife-led and obstetrician-led care by shifting existing tasks and responsibilities during labour could enhance personal continuity of care for women, possibly leading to fewer instrumental deliveries, less need for pain relief (Sandall et al., 2015) and more satisfaction among women (Rijnders et al., 2008).

The principal caregivers for women with low-risk pregnancies in the Netherlands are self-employed primary care midwives who work in private practices in, so-called midwife-led care. Women in primary care at onset of labour can choose to give birth 
Perdok, H., Jans, S., Verhoeven, C., Dillen C., Batenburg, R., Mol, B.W., Schellevis, F., Jonge, An de. Opinions of professionals about integrating midwife- and obstetrician-led care in The Netherlands. Midwifery: 2016, 37(6), 9-18

either at home or in a hospital under supervision of their primary care midwife. If a primary care midwife identifies a risk factor during pregnancy or labour, she will refer a woman to an obstetrician who takes over responsibility for her care: so-called obstetrician led care. In total, $85 \%$ of women start their pregnancy in midwife-led care and eventually $29 \%$ of all pregnant women give birth in midwife-led care (Stichting Perinatale Registratie Nederland, 2013a). Indications for referral to or consultation with an obstetrician during pregnancy and labour are listed in the national guideline "The List of Obstetric Indications" (Diemen: College voor Zorgverzekeringen, 2003). Women can be referred back to primary care when appropriate. However, about $50 \%$ of pregnant women starting in midwife-led care are referred at some stage during pregnancy and start labour in secondary care. The number of referrals during labour has increased steadily during the past years from $15 \%$ in 2010 (Stichting Perinatale Registratie Nederland, 2010) up to 23\% in 2013 (Stichting Perinatale Registratie Nederland, 2013b). This rise is mainly a result of more referrals for non-urgent reasons (Offerhaus et al., 2013), such as meconium stained liquor, the need for pain medication or failure to progress during the first stage of labour (Stichting Perinatale Registratie Nederland, 2013b).

The List of Obstetric Indications only distinguishes "high-risk" and "low-risk" indications. A "moderate risk" indication does not formally exist at present. In this study we defined referral indications with a high probability of good maternal and neonatal outcome (Perdok et al., 2015), such as the need for epidural anaesthesia for pain relief and meconium stained amniotic liquor, as "moderate risk". All women who develop "moderate risk" indications during labour are currently classified as "high risk", and referral takes place to an obstetrician, which means that care is handed over (Diemen: College voor Zorgverzekeringen, 2003). In daily practice the obstetrician often delegates the care to a clinical midwife (Cronie et al., 2012). The primary entry to practice qualification for midwifery in the Netherlands is a four year Midwifery degree, at higher professional education". On graduation midwives can choose to work as a primary care midwife providing full scope of practice care for women experiencing an uncomplicated pregnancy. Alternatively, midwives can choose to work within the hospital system as a clinical midwife under the responsibility of the obstetrician. Clinical midwives provide midwifery care for women, referred to obstetrician led care, who experience complications or have developed risk factors that require secondary care. Clinical midwives are experienced in additional tasks such as conducting continuous electronic fetal heart rate monitoring (EFM) and augmentation of labour. Clinical midwives deal with complicated pregnancy and birth, built on a foundational knowledge base through experience and work under the responsibility of an obstetrician. A postgraduate education to enable them to take on these "additional " tasks exists in the Netherlands and is expected to become obligatory in the near future. Of all births in obstetricianled care $40 \%$ are managed solely by a clinical midwife (Cronie et al., 2012).

Obstetricians will only be actively involved if additional risks or problems occur, such as fetal distress or the need to perform an operative childbirth. Obstetric nurses assist the midwife or doctor during labour in hospitals.

Countries such as New Zealand (Lee and Walker, 2011) and Canada (Canadian Association of Midwives, 2010) have a well-integrated primary and secondary care structure. Midwives move between primary and secondary care settings and continue to care for women transferred to secondary care, leading to more personal continuity 
Perdok, H., Jans, S., Verhoeven, C., Dillen C., Batenburg, R., Mol, B.W., Schellevis, F., Jonge, An de. Opinions of professionals about integrating midwife- and obstetrician-led care in The Netherlands. Midwifery: 2016, 37(6), 9-18

of care for women. In these two countries, midwives are trained and have the skills required to care for women who are transferred.

We hypothesise that if women with "moderate-risk" indications continue to receive care from their primary care midwife during labour, this will lead to more personal continuity of care, (Uijen et al., 2012) which is likely to increase women's birth satisfaction (Rijnders et al., 2008) and contribute to their feeling of safety during labour (de Jonge et al., 2014). In addition, this may lead to health benefits such as a reduction of medical interventions with a similar or lower rate of maternal and neonatal morbidity (Hodnett et al., 2007). If the primary care midwife were to provide care to women with a "moderate risk" indication this would require a major change in the organisation of Dutch maternity care and would need more collaboration between primary and secondary care with joint care pathways and additional tasks for the primary care midwife, such as the use of continuous EFM. Changes in tasks and responsibilities require consensus among all maternity care professionals involved. In the "INtegrated CAre System"(INCAS) study, the barriers and facilitators for integration of care during labour in the Netherlands were examined. In a Delphi-study with a panel of 50 professionals, we found a lack of consensus with regard to redistribution of responsibilities and tasks among Dutch maternity care professionals including primary care midwives, clinical midwives and obstetricians, and a wide variety of opinions about the ideal organisation of care (Perdok et al., 2014).

In the study reported here we followed up the previous Delphi study (Perdok et al., 2014) in order to investigate (a) the level of consensus among maternity care professionals regarding facilitators and barriers to integrate midwife-led and obstetrician-led care for women at "moderate risk" and (b) the level of consensus among maternity care professionals regarding tasks and responsibilities of professionals when caring for women with "moderate risk" factors.

\section{METHODS}

\section{Study design}

To obtain the opinions of maternity care professionals we developed an online questionnaire and in February/March 2013 invited midwives and obstetricians to complete this by sending them a link (Survey Monkey, Palo, Alto, CA, USA) via email. Non-responders received a reminder by e-mail after two weeks.

In the Netherlands a total number of 2852 midwives (Netherlands Institute for Health Services Research (NIVEL), 2014) and 942 obstetricians were active in maternity care, as of January 1, 2013. The majority of midwives (71\%), work in primary care and $29 \%$ work as a clinical midwife (Netherlands Institute for Health Services Research (NIVEL), 2014).

$84 \%$ of midwives in the Netherlands are members of the Royal Dutch Organisation of Midwives (KNOV) and nearly all obstetricians are member of the Dutch Society for Obstetrics and Gynaecology (NVOG). In order to reach an appropriate sample for the study, invitations were sent to members through both professional organisations. An e-mail with a link to an online questionnaire, was sent to a random sample of 400 midwives (300 primary care midwives and 100 clinical midwives) and to all 942 obstetricians between February and March 2013. More primary care midwives were invited compared to clinical midwives as this gives a good representation of current midwifery practice. The majority of Dutch obstetricians (gynaecologists) provide 
Perdok, H., Jans, S., Verhoeven, C., Dillen C., Batenburg, R., Mol, B.W., Schellevis, F., Jonge, An de. Opinions of professionals about integrating midwife- and obstetrician-led care in The Netherlands. Midwifery: 2016, 37(6), 9-18

obstetric care but only approximately 300 of them have obstetrics as their main field of practice. Due to privacy regulations it was not possible to select those who have obstetrics as their main field of practice. To reach an equal number of obstetricians with obstetrics as their main field of practice and midwives, 400 midwives were randomly selected. In the e-mail we specifically invited obstetricians with obstetrics as their main field of expertise to participate in the survey. Participation was anonymous.

The ethical committee of VU University Medical Centre Amsterdam, the Netherlands approved the study (reference 2011/252).

\section{The questionnaire}

A multidisciplinary project group consisting of obstetricians, midwives, an obstetric nurse, a paediatrician, a client representative and academic researchers acted as an advisory panel and approved all questions.

The questionnaire was based on the results of the previous Delphi study (Perdok et al., 2014).

The questionnaire consisted of 48 questions about the characteristics of professionals, a number of statements, and open-ended questions to identify unknown important determinants of successfully integrated care. The following topics were included: possible facilitators and barriers related to integration of maternity care,

distribution of responsibilities of maternity care professionals concerning care in case of "moderate risk" during labour in an integrated system (similar to Delphi study (Perdok et al., 2014), and specific questions related to education and skills of professionals concerning continuous EFM.

Participants were asked to indicate whether they considered a determinant to be a facilitator, a barrier or a neutral factor for integration of care and how influential they thought the determinant was on a Likert scale from 1 (very influential), 2 (influential), 3 (neutral score), 4 (not influential) to 5 (not at all influential). For the analysis, the categories 1 and 2 were combined as "influential" and 4 and 5 as "not influential".

To score the statements about the implementation of an integrated care system during labour and about the re-distribution of tasks and responsibilities of professionals concerning "moderate risk" indications during labour in an integrated system, participants were asked to rate their level of agreement on a Likert scale ranging from 1 (totally agree), 2 (agree), 3 (neutral score), 4 (disagree) to 5 (totally disagree). For the analysis, 1 and 2 were combined as "agreement" and 4 and 5 were combined as "disagreement". Next, "consensus" for each statement was defined as agreement or disagreement by more than $70 \%$ among all panel members and more than $50 \%$ agreement or disagreement within each professional group.

In the statements a distinction was made between "taking care of women" and "being totally responsible for women's care".

\section{Data analysis}

Descriptive statistics were used for the analysis. A p-value of $<0.05$ was considered statistically significant when testing differences between subgroups. Analyses were conducted by calculating the proportion of professionals who indicated a determinant as influential and the percentage of agreement or disagreement for the total group. 
Perdok, H., Jans, S., Verhoeven, C., Dillen C., Batenburg, R., Mol, B.W., Schellevis, F., Jonge, An de. Opinions of professionals about integrating midwife- and obstetrician-led care in The Netherlands. Midwifery: 2016, 37(6), 9-18

These analyses were conducted separately for primary care midwives, clinical midwives and obstetricians if more than $60 \%$ of the participants answered the determinant as influential. The data were analysed in SPSS version 19.0 (SPSS, Inc., Chicago, IL, USA).

\section{FINDINGS}

A total number of 442 professionals responded of which 18 respondents were excluded because their questionnaires were incomplete. Questionnaires of 424 professionals were included in the analysis. The response rate was $44 \%(n=131)$ amongst primary care midwives, $51 \%(n=51)$ amongst clinical midwives and $25 \%$ $(\mathrm{n}=242)$ amongst obstetricians (Table 1). Of the responding obstetricians $89 \%$ $(\mathrm{n}=215)$ had obstetrics as their main field of practice.

\section{[TABLE 1]}

\section{Facilitators and barriers}

In the free text section many professionals expressed a positive attitude towards integrating care. Consensus was observed on six statements of which five were considered facilitating factors and one was considered a barrier for integrating midwife-led and obstetrician-led care during labour (Table 2).

\section{[TABLE 2]}

Consensus was observed on the following statements: the role of each professional is well-defined and each professional is personally responsible for his/her own tasks (86\%, facilitator), all caregivers use a joint electronic client record system ( $98 \%$, facilitator); the management of care for all pregnant women is discussed with all primary and secondary caregivers in a structured manner (78\%, facilitator); after referral from midwife-led to obstetrician-led care, it is important to minimise the number of health care professionals involved ( $82 \%$, facilitator), the use of a "care pathway" will support a consistent and unequivocal policy (79\%, facilitator) and financial motives could interfere with the implementation of integrated care during labour ( $72 \%$, barrier).

No consensus was observed on the women's freedom of choice for the place of birth for low risk women (either at home or in the hospital). The majority of primary care midwives (78\%) and clinical midwives (70\%) agreed that low risk women should be able to choose to give birth either at home or in hospital while $48 \%$ of the obstetricians agreed with this. Equally, $71 \%$ of the obstetricians agreed that a birth centre could be an alternative for home birth while fewer primary care midwives and clinical midwives did (37\% and $44 \%$ respectively). No consensus was observed on the women's freedom of choice for the place of birth in case the need for pain relief arises during labour. Most primary care midwives agreed $(80 \%)$ that being able to give medical pain relief in a birth centre is a facilitating factor for integrating care, whereas of the obstetricians only $44 \%$ agreed with this statement. Regarding the training of midwives to assist women with a moderate risk indication (e.g. training in EFM) there was also discrepancy in the opinions of professionals: $54 \%$ of the obstetricians believed that primary care midwives should be trained to assist these women compared to $83 \%$ of primary care midwives and $67 \%$ of clinical midwives. 
Perdok, H., Jans, S., Verhoeven, C., Dillen C., Batenburg, R., Mol, B.W., Schellevis, F., Jonge, An de. Opinions of professionals about integrating midwife- and obstetrician-led care in The Netherlands. Midwifery: 2016, 37(6), 9-18

Participants were asked how much training is needed to interpret EFM. According to the participants, clinical midwives and medical trainees need to have assisted at least 80 (SD 95) women with EFM to be competent enough and should assist a minimum of 61 (SD 59) women to give birth with EFM annually to remain competent. For the primary care midwife, the mean reported duration of training for interpreting EFM was 15 weeks (data not shown).

\section{Implementation of integrated care}

Concerning facilitating factors for the organisation of care, nearly $80 \%$ of obstetricians and clinical midwives agreed that all professionals involved in both midwife-led care and obstetrician-led care should work within one organisation independent of the hospital organisation (as opposed to private or independent practice) compared to $48 \%$ of primary care midwives.

\section{Tasks and responsibilities}

Table 3 shows the opinions of different professionals regarding the management and responsibilities in case of "moderate risk" indications. Most consensus was observed on the statements regarding the role of the clinical midwife.

[table 3]

Primary care midwives agreed that they can provide care to women with "moderate risk" indications. However, obstetricians and clinical midwives did not consider this to be an appropriate role for primary care midwives. None of the professional groups, including primary care midwives themselves, thought that primary care midwives should be responsible for the care of women with moderate risk indications. According to most respondents, the clinical midwife is the most appropriate professional to care for women with a "moderate risk" indication. Consensus on this was observed for all indications except for thin meconium stained amniotic liquor. Clinical midwives themselves agreed that they could be responsible for the care for women with "moderate risk" indications, but no consensus was observed in the overall group.

\section{DISCUSSION}

This study confirms and quantifies the previous findings from our Delphi study (Perdok et al., 2014), which showed that maternity care professionals are positive about integrating maternity care in the Netherlands, but they do not agree on the characteristics of such a system nor the corresponding tasks and responsibilities of the different care providers. All professional groups agreed with the statement that clinical midwives are the appropriate caregivers for most women with "moderate risk" indications. In the current study we observed agreement on the importance of an electronic client record system as well as the importance of strong collaboration between professionals. Respondents reported that although individuals remain responsible for their own actions, teamwork is considered to be important. Respondents largely agreed with the statement that conflicting interests exist related to the payment structure, which may form a barrier for integrating care.

This study is the first large-scale evaluation in the Netherlands that gives insight into the opinions of maternity care professionals working or planning to work in an integrated care setting. It is vital to take the opinions of numerous professionals involved into account for a successful integration of midwife-led and obstetrician-led care. When comparing the results of this study and the Delphi study (Perdok et al., 
Perdok, H., Jans, S., Verhoeven, C., Dillen C., Batenburg, R., Mol, B.W., Schellevis, F., Jonge, An de. Opinions of professionals about integrating midwife- and obstetrician-led care in The Netherlands. Midwifery: 2016, 37(6), 9-18

2014), the following factors must be taken into account: firstly, the current study was carried out one year after the Delphi study which means that the process of integrating care was at a somewhat further stage and secondly, this study shows the opinions of a sample of midwives and obstetricians willing to respond whereas the panel members in the Delphi study could be considered leaders in the field with regards to this topic. Knowledge about professionals' opinions is important for other countries as well where changes in the maternity care system are being implemented. Preferably we would have sent the invitation to the subgroup of obstetricians with obstetrics as their main field of practice only. However, due to privacy regulations this was not possible and therefore all obstetricians were approached. In the invitation we stated that we were particularly interested in the views of obstetricians who are experts in obstetrics. As the majority of obstetricians are sub-specialized in gynaecological care this may have led to the lower response rate of the obstetricians compared to the group of midwives. However the number of responders was high enough to provide valid insights. Since the random sample of midwives was selected from a list of all midwives in the Netherlands we consider this to be a representative group.

Professionals seem to be reluctant to change the system, as their opinions about many statements regarding responsibilities of professionals were consistent with the current system (Diemen: College voor Zorgverzekeringen, 2003). Moreover, in 13\% of the statements "neutral" was the most frequently given answer, which can be interpreted as not having an opinion about the statement. Perhaps this resistance to change might be due to professionals having difficulty to envisage a different system if they do not know what the consequences will be for their professional position or income (NHS Institute for Innovation and Improvement 2008, 2008). A survey among midwives in Australia showed that most participants found it difficult to conceptualise how they might contribute to system change. In addition, the majority passively accepted their status and believed they were powerless to effect change (Sidebotham et al., 2015). This might be the case with primary care midwives in this study, as they are prepared to give care but not to carry responsibility in case of a moderate risk indication, which is in line with the current system. As people are more likely to use new ways of organising, thinking and acting, if they are actively involved in the decision-making process in a bottom-up approach (Hart and Anthrop, 1996) it may be important to involve professionals from the start when changing the maternity care system. Strong midwifery leadership is needed to enable midwives to re-conceptualise roles and work patterns and identify how they can contribute to reform maternity services (Sidebotham et al., 2015). We expect that this counts for all health care professionals. The general idea that people are naturally reluctant to change must be taken into account when interpreting the results in this study and when reorganising a maternity care system.

This study shows that professionals involved in maternity care in the Netherlands consider continuity of care to be important. Three types of continuity of care have been described: care from the same provider who knows and follows the woman (personal continuity), good communication and cooperation between care providers in one care setting (team continuity), and good communication and cooperation between care providers in different care settings (cross-boundary continuity) (Uijen et al., 2012). It is not surprising that in our study cross-boundary continuity was found to be important as integrated care aims to improve cooperation between 
Perdok, H., Jans, S., Verhoeven, C., Dillen C., Batenburg, R., Mol, B.W., Schellevis, F., Jonge, An de. Opinions of professionals about integrating midwife- and obstetrician-led care in The Netherlands. Midwifery: 2016, 37(6), 9-18

professionals in midwife-led and obstetrician-led care. Examples of cross-boundary continuity are working with electronically available client records, shared care pathways and the more collective decision-making. This is in agreement with other literature showing that collaboration between professionals is thought to be important (Prins et al., 2014). Consensus was also observed on the statement about personal continuity: it is important to minimise the number of professionals $(82 \%)$. In line with this, qualitative research shows that clients appreciate the continuing care of the primary care midwife after referral (de Jonge et al., 2014 and Faber et al., 2014). As found in the Delphi study (Perdok et al., 2014), midwives and obstetricians agreed that the clinical midwife is the most appropriate professional to care for women with a "moderate risk" indication. However, when compared to the Delphi study(Perdok et al., 2014) this study found less consensus in the overall group with regards to the clinical midwife also being responsible for women without direct involvement of an obstetrician. A reason for this could be growing anxiety among professionals in this study possibly due to recent disciplinary action by the national complaints commission when tasks were delegated (Medisch Contact, 2015). This study shows that the clinical midwife herself does feel confident in being responsible for most moderate risk indications, more so in the current study when compared to the Delphi study. This could be explained by the fact that, at the time of this study, more clinical midwives had received additional training in using medical interventions such as epidural anaesthesia or the administration of remiphentanyl, and thus feel more confident in taking care of this group of women. Surprisingly, consensus was observed for the clinical midwife to provide care to women with thick meconium stained liquor although not for thin meconium stained liquor. No consensus was observed for the care of women with thin meconium because only a minority of primary care midwives agreed with clinical midwives to take care of this group. This could indicate a domain struggle between primary and clinical midwives when integrated care is being introduced in regions.

A seemingly contradictory outcome was observed in this study. Although the primary care midwife was willing to extend her tasks (e.g. provide care to women with a request for pain relief and EFM), she was not willing to take on full responsibility for women with a moderate risk indication. This is not in line with prior research (Perdok et al., 2014), nor the other outcomes in this study in which the majority of primary care midwives state that professionals are individually responsible for the care they provide. Again, this could be explained by resistance to change if they cannot envisage the consequences. Although midwife-led care has been shown to lead to better birth outcomes and more continuity of care compared to shared care (Sandall et al., 2015) and a lower risk of severe acute maternal morbidity compared to obstetrician-led care (de Jonge et al., 2015) for women without substantial medical or obstetric complications, our study shows that primary care midwives are not yet ready to extend their responsibilities.

This is consistent with the low rate $(21 \%)$ of primary care midwives who were prepared to refer women directly to an anaesthesist without consulting an obstetrician first. Most professionals in this study indicated that an obstetrician must be consulted before referring to an anaesthesist for epidural analgesia. This is different to other countries where midwives consult the anaesthesist directly for epidural analgesia as pain management during normal labour. In Canada, midwives who have acquired the appropriate knowledge, skills and judgment are permitted to monitor and manage 
Perdok, H., Jans, S., Verhoeven, C., Dillen C., Batenburg, R., Mol, B.W., Schellevis, F., Jonge, An de. Opinions of professionals about integrating midwife- and obstetrician-led care in The Netherlands. Midwifery: 2016, 37(6), 9-18

clients with epidural analgesia after consulting the anaesthesist (College of Midwives of Ontario, 2000). As long as there is no indication for transfer of care to an obstetrician, the Canadian midwife remains the primary caregiver, thereby enhancing continuity of care. This could be an example for the Netherlands.

If primary care midwives continue to care for women when a "moderate risk" arises, it is necessary that they are educated for additional tasks such as EFM. The primary care midwife in the Netherlands currently uses intermittent auscultation to assess the fetal condition during normal labour. Although continuous EFM has been shown to have low accuracy (Abdulhay et al., 2014; Nederlandse Vereniging Obstetrie en Gyneacologie and NVOG richtlijn, goedkeuring 2014-05-19) and does not improve perinatal outcomes among low risk women (NHS Guideline Obs 21, 2012), it is widely used across the world to monitor the fetal condition during labour. Our study shows that primary care midwives are willing to extend their tasks but no consensus was observed on the primary care midwife being the suitable caregiver to use and to interpret EFM, which is supported by previous research (Perdok et al., 2014). Surprisingly, there is no educational standard with regards to EFM training. Internationally agreed standards for EFM training and number of EFM's are needed and may contribute to the quality of maternity care.

The quality of care delivered by non-clinician health professionals is not inferior compared to clinicians (Naylor and Kurtzman, 2010). However, our study shows that obstetricians (clinicians) and clinical midwives (non-clinician health professional) do not agree with the extension of tasks of the primary care midwife (non-clinician health professional) such as EFM. Agreement amongst obstetricians was higher regarding the clinical midwife extending her tasks. However, these midwives work under the responsibility of obstetricians and not autonomously like primary care midwives. Findings by another study (Donelan et al., 2013) were similar to ours showing that the majority of nurse practitioners expressed their ability to practice independently as leaders of patient-centred medical homes but this was not reflected in the attitudes of the majority of clinicians. Donelan (Donelan et al., 2013) describes that it is not surprising (and indeed may even be expected) that clinicians and nonclinician health professionals emerge without a common vision of their roles in the provision of primary care as these professionals come from very different cultures of professional education, are guided by different theoretical perspectives, and often develop their clinical skills in different practice environments. Other reasons for the different vision with regards to extension of tasks could be that clinical midwives are afraid of becoming redundant whereas obstetricians may fear the loss of control. Nonetheless, if primary care midwives were to provide care to women with a moderate risk indication after appropriate training this would improve continuity of midwife-led caregiver. However, task shifting can only be achieved if obstetricians are willing to give up tasks and non-clinicians health professionals (midwives) are able to perform these tasks (Freund et al., 2015). As well as this, fee-for-service schemes may be a barrier to role expansion of non-clinician health professionals (midwives) if only services delivered by clinicians (obstetricians) are reimbursed (Freund et al., 2015).

Internationally the safety of home births and midwife-led care is now positively being discussed (Shah, 2015). However, significant differences remain between opinions of maternity care professionals regarding home birth. Our study confirms research findings (McNutt et al., 2014 and Vedam et al., 2012) showing a strong 
Perdok, H., Jans, S., Verhoeven, C., Dillen C., Batenburg, R., Mol, B.W., Schellevis, F., Jonge, An de. Opinions of professionals about integrating midwife- and obstetrician-led care in The Netherlands. Midwifery: 2016, 37(6), 9-18

support from the midwifery community regarding home birth for low risk women but that obstetricians have a neutral or negative opinion and prefer women giving birth in a hospital or in a birth centre. A Canadian study showed that the attitude of maternity caregivers is associated with exposure to home birth; clinicians believed home birth to be less safe than hospital birth (Vedam et al., 2012). It is known that views of caregivers have significant impact on the extent to which women are able to make informed decisions (Floyd, 1995). In order for medical trainees to broaden their view on the organisation of the Dutch obstetric system it is important that they experience home birth. This may be achieved by undertaking training within a primary care practice (Mensch et al., 2015). Sufficient exposure to home birth may enable medical trainees to give a more informed choice of birth place to women and more insight into the tasks of colleagues working in primary care.

Health care systems with a strong focus on primary care, such as the Dutch system, achieve a high-quality and cost-effective healthcare system (Kringos et al., 2013) and provide better population health compared to systems without primary care (Starfield, 2012). The WHO advocates a switch from specialized to generalist ambulatory care, whereby generalists are responsible for a defined population and are able to co-ordinate support from hospitals (The World Health Organisation, Geneva, 2008). Taking this into account, the role of the primary care midwife could be merged with the role of the clinical midwife. This would contribute to personal continuity of care but would require a major change in the Dutch maternity care system. Still, the system in New Zealand could be used as an example where primary and clinical midwives use the same protocols and the same midwife continues to take care of women with a "moderate risk" indication (Lee and Walker, 2011). Additional tasks, such as working with EFM and ultrasound screening could be part of the regular midwifery training contributing to the quality of maternity care. To prepare student midwives for the full scope of practice in the community and in hospitals, the midwifery training could be upgraded to a university degree like in Canada (Canadian Association of Midwives, 2015). Additional training may give the primary care midwife more confidence and willingness to extend their responsibilities.

\section{CONCLUSION}

This study shows that professionals are positive about the implementation of an integrated maternity care system in the Netherlands but no consensus exists about the characteristics of such a system. Consensus was observed on the clinical midwife being an appropriate caregiver for most women with a "moderate risk" indication but no consensus was observed with regards to the clinical midwife being responsible for women without direct involvement of an obstetrician. Although the primary care midwife is willing to expand her skills in order to improve continuity of care, no consensus was observed on extension of her tasks and responsibilities.

The results of this study are in accordance with earlier research, which shows that it is not yet possible to design a blueprint for an integrated maternal care model in the Netherlands. To bring about change in a maternity care system, an implementation strategy should be chosen that accounts for differences in interests and opinions between professionals.

In addition, primary care midwives need to gain confidence before they are willing to take on additional responsibilities for women with moderate risk indications. 
Perdok, H., Jans, S., Verhoeven, C., Dillen C., Batenburg, R., Mol, B.W., Schellevis, F., Jonge, An de. Opinions of professionals about integrating midwife- and obstetrician-led care in The Netherlands. Midwifery: 2016, 37(6), 9-18

\section{DISCLOSURE OF INTERESTS}

The authors declare that they have no competing interests.

\section{CONTRIBUTION TO AUTHORSHIP}

HP, BWM and AJ designed the study. HP wrote the article. HP and SJ conducted the analyses. HP, SJ, CV, JD, RB, BWM FS and AJ contributed to the interpretation of the data. SJ, CV, JD, RB, BWM, FS and AJ critically revised earlier drafts of the paper for important intellectual content and gave final approval of the version to be published.

\section{FUNDING}

The study was funded by ZonMw, the Dutch organisation for health research and development ( ZonMw, reference 2011/252).

\section{ACKNOWLEDGEMENTS}

We greatly appreciate all members of the INCAS project group and M. Westerneng for their constructive comments on the design and results of the study. The project group consisted of twelve members including obstetricians, midwives, an obstetric nurse, a paediatrician, a client representative and researchers.

Members of the INCAS project group were:

Ronald Batenburg, $\mathrm{PhD}$; Siep de Boer $\uparrow$, MD; Jeroen van Dillen, $\mathrm{MD}, \mathrm{PhD}$; Corrie Hartog; Anne van Kempen, PhD; Prof. Ben Willem Mol, PhD., MD; Marianne Nieuwenhuijze, RM, MPH; Pien Offerhaus, RM, MSc; Marlies Rijnders, RM, PhD; Corine Verhoeven, RM, PhD; Rachel Verweij, Ir.; Therese Wiegers, PhD

\section{REFERENCES}

Abdulhay, E.W.,Oweis,R.J.,Alhaddad,A.M.,Sublaban,F.N.,Radwan,M.A.,Alma- saeed, H.M.,2014.Reviewarticle:non-invasivefetalheartratemonitoring techniques.BiomedicalScienceandEngineering2,53-67.

Canadian AssociationofMidwives,2010.Positionstatement.Midwiferycareand normal birth. 〈/http://www.canadianmidwives.org/DATA/DOCUMENT/CAM_

ENG_Midwifery_Care_Normal_Birth_FINAL_Nov_2010.pdf) . Accessed01/12 2016.

Canadian AssociationofMidwives,2015.MidwiferyEducationinCanada. (cana dianmidwives.org/midwifery-education). (accessed05.15.15.).

College ofMidwivesofOntario,2000.IndicationsforMandatoryDiscussion, Con- sultation andTransferofCare.

Cronie, D.,Rijnders,M.,Buitendijk,S.,2012.Diversityinthescopeandpracticeof hospital-based midwivesintheNetherlands.JournalofMidwifery\&Women's Health 57,469-475.

Diemen: CollegevoorZorgverzekeringen,2003.VerloskundigVademecum.

Donelan, K.,DesRoches,C.M.,Dittus,R.S.,Buerhaus,P.,2013.Perspectivesofphy- sicians andnursepractitionersonprimarycarepractice. TheNewEngland Journal ofMedicine368,1898-1906.

Evers, A.C.,Brouwers,H.A.,Hukkelhoven,C.W.,Nikkels,P.G.,Boon,J.,vanEgmond- Linden, A.,Hillegersberg,J.,Snuif,Y.S.,Sterken-Hooisma,S.,Bruinse,H.W., Kwee,

A.,2010.Perinatalmortalityandseveremorbidityinlowandhighrisk termpregnanciesintheNetherlands:prospectivecohortstudy.BritishMedical Journal $341, \mathrm{c} 5639$.

Faber,M.,Grande,S.,Wollersheim,H.,2014.Narrowingthegapbetweenorgani- sational demandsandthequestforpatientinvolvement:thecaseforcoordinatedpathways. InternationalJournalofCareCoordination17,72-78.

Floyd, L.,1995.Communitymidwives'viewsandexperienceofhomebirth.Mid- wifery 11,3-10. 
Perdok, H., Jans, S., Verhoeven, C., Dillen C., Batenburg, R., Mol, B.W., Schellevis, F., Jonge, An de. Opinions of professionals about integrating midwife- and obstetrician-led care in The Netherlands. Midwifery: 2016, 37(6), 9-18

Freund,T.,Everett,C.,Griffiths, P.,Hudon,C.,Naccarella,L.,Laurant,M.,2015.Skill mix, rolesandremunerationintheprimarycareworkforce:whoarethe healthcare professionalsintheprimarycareteamsacrosstheworld? Interna- tional JournalofNursingStudies52,727-743.

Hart, E.,Anthrop,C.,1996.Actionresearchasaprofessionalizingstrategy:issues and dilemmas.JournalofAdvancedNursing23,454-461.

Hodnett, E.D.,Gates,S.,Hofmeyr,G.J.,Sakala,C.,2007.Continuoussupportfor women duringchildbirth.CochraneDatabaseofSystematicReviews, CD003766.

de Jonge,A.,Stuijt,R.,Eijke,I.,Westerman,M.J.,2014.Continuityofcare:what matterstowomenwhentheyarereferredfromprimarytosecondarycare during labour?aqualitativeinterviewstudyintheNetherlands.BMCPreg- nancy andChildbirth14,103.

de Jonge,A.,Mesman,J.A.,Mannien,J.,Zwart,J.J.,Buitendijk,S.E.,vanRoosmalen,J., vanDillen,J.,2015.Severeadversematernaloutcomesamongwomenin midwife-led versusobstetrician-ledcareattheonsetoflabourintheNether- lands: anationwidecohortstudy.PLoSOne10,e0126266.

Kringos, D.,Boerma,W.,Bourgueil,Y.,Cartier,T.,Dedeu,T.,Hasvold,T.,Hutchinson, A.,Lember,M.,Oleszczyk,M.,RotarPavlic,D.,Svab,I.,Tedeschi,P.,Wilm,S.,

Wilson, T.A.,Windak,A.,VanderZee,J.,Groenewegen,P.,2013.Thestrengthof primary careinEurope:aninternationalcomparativestudy. TheBritishJournal of GeneralPractice:TheJournaloftheRoyalCollegeofGeneralPractitioners63, e742-e750.

Lee, D.D.,Walker,K.,2011.Case-loadingmidwiferyinNewZealand:bridgingthe normal/abnormal divide'withwoman'.Midwifery27,46-52.

McNutt,A.,Thornton,T.,Sizer,P.,Curley,A.,Clarke,P.,2014.OpinionsofUKperi- natal healthcareprofessionalsonhomebirth.Midwifery30,839-846.

Medisch Contact,2015.Gynaecoloogberisptalsopdrachtgeverklinischverlos- kundige. 15.

Mensch C.S.,RossenG.,vanderLeeN.,vanDillenJ.,2015.Stageeerstelijnsver- loskundige zorgvoorAlOSgynaecologie,vol.128.pp.169-172.

Naylor,M.D.,Kurtzman,E.T.,2010.Theroleofnursepractitionersinreinventing primary care. HealthAffairs29,893-899.

NederlandseVerenigingObstetrieenGyneacologie,NVOGrichtlijn,goedkeuring 2014-0519.Intrapartumfoetalebewakingaterme.

NetherlandsInstituteforHealthServicesResearch(NIVEL),2014.Registrationof midwives2013.refworks.com/refworks2.(accessed8.02.15.)2015.

NHS GuidelineObs21,2012.AntenatalFetalMonitoring. 〈/http://www.wwl.nhs.uk/ Library/FOI/Requests/2012_2013/October_2012/1398_GuidelineObs21_Antena tal_Fetal_Monitoring.pdf)〉. Accessed03-172015.

NHS InstituteforInnovationandlmprovement2008,2008.QualityandService improvementTools. 〈/http://www.institute.nhs.uk/quality_and_service_im provement_tools/quality_and_service_improvement_tools/resistance_-_under standing_it.html\#sthash.X8EIEggX.dpuf $\rangle)$. (accessed03.19.15).

Offerhaus, P.M.,Hukkelhoven,C.W.,deJonge,A.,vanderPal,K.,Scheepers,P.L., LagroJanssen, A.L.,2013.Persistingriseinreferralsduringlaborinprimary midwife-led careintheNetherlands.Birth40,192-201.

Perdok, H.,Jans,S.,Verhoeven,C.,vanDillen,J.,Mol,B.W.,deJonge,A.,2015.In- trapartum referralfromprimarytosecondarycareintheNetherlands:aretrospectivecohortstudyonmanagementoflaborandoutcomes.Birth.

Perdok, H.,Mokkink,L.,van,D.J.,Westerneng,M.,Jans,S.,Mol,B.W.,de,J.A.,2014. Opinions ofmaternitycareprofessionalsaboutintegrationofcareduringlabor for "moderaterisk"indications:aDelphistudyintheNetherlands.Birth41, 195-205.

Prins, M.,vanDillen,J.,deJonge,A.,2014.AdvantagesofMidwife-ledContinuity Model ofcareobr /4obr /4obr /4. PMID:25017977157,A7070.

Rijnders,M.,Baston,H.,Schonbeck,Y.,vanderPal,K.,Prins,M.,Green,J.,Buitendijk, S., 2008.Perinatalfactorsrelatedtonegativeorpositiverecallofbirthex- perience inwomen3yearspostpartumintheNetherlands.Birth35,107-116.

Sandall, J.,Soltani,H.,Gates,S.,Shennan,A.,Devane,D.,2015.Midwife-ledcon- tinuity modelsversusothermodelsofcareforchildbearingwomen.Cochrane Database ofSystematicReviews9,CD004667. 
Perdok, H., Jans, S., Verhoeven, C., Dillen C., Batenburg, R., Mol, B.W., Schellevis, F., Jonge, An de. Opinions of professionals about integrating midwife- and obstetrician-led care in The Netherlands. Midwifery: 2016, 37(6), 9-18

Shah, N.,2015.ANICEdelivery-the cross-Atlanticdivideovertreatmentintensity in childbirth.TheNewEnglandJournalofMedicine372,2181-2183.

Sidebotham, M.,Fenwick,J.,Rath,S.,Gamble,J.,2015.Midwives'perceptionsof their rolewithinthecontextofmaternityservicereform:anappreciativeinquiry.WomenandBirth:JournaloftheAustralianCollegeofMidwives.

Starfield B.,2012.Primarycare:anincreasinglyimportantcontributortoeffectiveness, equity, andefficiency ofhealthservices.SESPASReport2012.Gaceta sanitaria/S.E.S.P.A.S26,20-6.

StichtingPerinataleRegistratieNederland,2010.JaarboekZorginNederland2008. StichtingPerinataleRegistratieNederland,2013a.PerinataleZorginNederland 2010. StichtingPerinataleRegistratieNederland,2013b.PerinatalezorginNederland 2013. 〈〈www.perinatreg.nl/uploads/150/153/PRN_jaarboek_2013_09122014. pdf †). (accessed02.7.15.).

The WorldHealthOrganisation, Geneva,2008.TheWorldHealthreport2008. 2008.

Uijen,A.A.,Bosch,M.,vandenBosch,W.J.,Bor,H.,Wensing,M.,Schers,H.J.,2012. Heart failurepatients'experienceswithcontinuityofcareanditsrelationto medication adherence:across-sectionalstudy.BMCFamilyPractice13,86.

Vedam, S.,Schummers, L.,Stoll,K.,Rogers,J.,Klein,M.C.,Fairbrother,N.,Dharamsi, S., Liston,R.,Chong,G.K.,Kaczorowski,J.,2012.TheCanadianBirthPlaceStudy: describing maternitypracticeandproviders'exposuretohomebirth.Mid- wifery 28,600-608.

Wiegers, T.A.,2009.Thequalityofmaternitycareservicesasexperiencedbywo- men intheNetherlands.BMCPregnancyandChildbirth9,18. 
Perdok, H., Jans, S., Verhoeven, C., Dillen C., Batenburg, R., Mol, B.W., Schellevis, F., Jonge, An de. Opinions of professionals about integrating midwife- and obstetrician-led care in The Netherlands. Midwifery: 2016, 37(6), 9-18

\section{TABLES AND FIGURES}

Table 1.

Characteristics of respondents.

\begin{tabular}{l|c|c|c|} 
& \multicolumn{1}{c}{$\begin{array}{l}\text { Primary care } \\
\text { midwives }\end{array}$} & $\begin{array}{l}\text { Clinical } \\
\text { midwives }\end{array}$ & Obstetricians \\
\hline $\begin{array}{l}\text { Respondents } \\
N\end{array}$ & 131 & 51 & 242 \\
\hline$\%$ & 44 & 51 & 25 \\
\hline $\begin{array}{l}\text { Mean age in years (SD) } \\
\text { Mean work experience (years) }\end{array}$ & $37.0^{*}(10,6)$ & $41.4^{*}(10,1)$ & $47.2^{*}(\mathrm{SD}$ \\
\hline $\begin{array}{l}\text { Urbanisation level of the } \\
\text { practise/hospital (\%) }\end{array}$ & $11.8^{*}$ & & $8,9)$ \\
\hline $\begin{array}{l}\text { Urban } \\
\text { Middle sized towns }\end{array}$ & & & $15.4^{*}$ \\
\hline $\begin{array}{l}\text { Rural } \\
\text { Employment (\%) }\end{array}$ & $30.5^{*}$ & $45.1^{*}$ & \\
\hline $\begin{array}{l}\text { Employed by private practise } \\
\text { Employed by hospital }\end{array}$ & $30.5^{*}$ & $47.1^{*}$ & $26.4^{*}$ \\
\hline
\end{tabular}

Total respondents 424

* $\quad p<0.05$ 
Perdok, H., Jans, S., Verhoeven, C., Dillen C., Batenburg, R., Mol, B.W., Schellevis, F., Jonge, An de. Opinions of professionals about integrating midwife- and obstetrician-led care in The Netherlands. Midwifery: 2016, 37(6), 9-18

Table 2

Opinions about the facilitators and barriers of an integrated matemity care system of professionals.

\begin{tabular}{|c|c|c|c|c|c|c|}
\hline \multirow[t]{2}{*}{ Statement } & \multicolumn{4}{|c|}{$\begin{array}{l}\text { Opinion per professional } \\
\text { group } \\
(\%)\end{array}$} & \multirow{2}{*}{$\begin{array}{l}\text { Total } \\
\text { group } \\
(\%) \\
n=424\end{array}$} & \multirow[t]{2}{*}{ Consensus } \\
\hline & & \begin{tabular}{|l|l|}
0 \\
$n=242$ \\
\end{tabular} & \begin{tabular}{|l|l|}
$P$ \\
$n=131$ \\
\end{tabular} & $\mathrm{C}_{n=51}$ & & \\
\hline \multicolumn{7}{|l|}{ Vision } \\
\hline $\begin{array}{l}\text { The vision of maternity care professionals is very } \\
\text { diverse: some concentrate on the physiological } \\
\text { process, whereas others concentrate on the risks } \\
\text { that might occur }\end{array}$ & $\begin{array}{l}\mathbf{F} \\
\mathbf{B}\end{array}$ & $\begin{array}{l}11 \\
63\end{array}$ & $\begin{array}{l}16 \\
74\end{array}$ & $\begin{array}{l}16 \\
63\end{array}$ & $\begin{array}{l}67 \\
\text { barricr }\end{array}$ & No \\
\hline $\begin{array}{l}\text { Obstetricians and midwives both work } \\
\text { autonomously }\end{array}$ & $\begin{array}{l}\mathbf{F} \\
\mathbf{B}\end{array}$ & $\begin{array}{l}16 \\
49 \\
\end{array}$ & $\begin{array}{l}39 \\
30\end{array}$ & $\begin{array}{l}37 \\
37\end{array}$ & $\begin{array}{l}42 \\
\text { barrier }\end{array}$ & No \\
\hline $\begin{array}{l}\text { All maternity care professionals are personally } \\
\text { responsible for the care they provide }\end{array}$ & $\begin{array}{l}\text { F } \\
\text { B }\end{array}$ & $\begin{array}{l}45 \\
15 \\
\end{array}$ & $\begin{array}{l}71 \\
12 \\
\end{array}$ & $\begin{array}{l}67 \\
12 \\
\end{array}$ & $\begin{array}{l}56 \\
\text { facilitator } \\
\end{array}$ & No \\
\hline $\begin{array}{l}\text { Low risk women can chose the place of birth: } \\
\text { either at home or in hospital }\end{array}$ & $\begin{array}{l}\mathbf{F} \\
\mathbf{B} \\
\end{array}$ & $\begin{array}{l}48 \\
14 \\
\end{array}$ & \begin{tabular}{|l|}
78 \\
4 \\
\end{tabular} & $\begin{array}{l}70 \\
7 \\
\end{array}$ & $\begin{array}{l}60 \\
\text { facilitator } \\
\end{array}$ & No \\
\hline $\begin{array}{l}\text { In an integrated system, a birth centre could be an } \\
\text { alternative for a home birth for all women at low } \\
\text { risk for complications }\end{array}$ & $\begin{array}{l}\mathbf{F} \\
\mathbf{B}\end{array}$ & $\begin{array}{l}71 \\
7\end{array}$ & $\begin{array}{l}37 \\
51\end{array}$ & $\begin{array}{l}44 \\
19\end{array}$ & $\begin{array}{l}58 \\
\text { facilitator }\end{array}$ & No \\
\hline $\begin{array}{l}\text { In an integral care system, a birth centre could be } \\
\text { a possible alternative location where pain relief } \\
\text { can be administered }\end{array}$ & $\begin{array}{l}\mathbf{F} \\
\mathbf{B}\end{array}$ & $\begin{array}{l}44 \\
28\end{array}$ & $\begin{array}{l}80 \\
6\end{array}$ & $\begin{array}{l}56 \\
26\end{array}$ & $\begin{array}{l}57 \\
\text { facilitator }\end{array}$ & No \\
\hline $\begin{array}{l}\text { Re-arrangement of tasks within midwife-led and } \\
\text { obstetrician-led care could lead to a different }\end{array}$ & $\begin{array}{l}\mathbf{F} \\
\mathbf{B}\end{array}$ & $\begin{array}{l}60 \\
18 \\
\end{array}$ & $\begin{array}{l}64 \\
17 \\
\end{array}$ & $\begin{array}{l}51 \\
35\end{array}$ & \begin{tabular}{|l|}
60 \\
facilitator
\end{tabular} & No \\
\hline \multicolumn{7}{|l|}{ role for the primary care midwife } \\
\hline \multicolumn{7}{|l|}{ Characteristics Organisation } \\
\hline $\begin{array}{l}\text { To enable an integrated care system, all } \\
\text { caregivers involved in the care for pregnant } \\
\text { women, are organised within one independent } \\
\text { organisation }\end{array}$ & $\begin{array}{l}\mathbf{F} \\
\mathbf{B}\end{array}$ & $\begin{array}{l}76 \\
8\end{array}$ & $\begin{array}{l}48 \\
21\end{array}$ & $\begin{array}{l}79 \\
8\end{array}$ & $\begin{array}{l}68 \\
\text { facilitator }\end{array}$ & No \\
\hline $\begin{array}{l}\text { An integrated care system is a well-structured } \\
\text { hierarchal organisation, in which responsibilities } \\
\text { for the care are clearly defined }\end{array}$ & $\begin{array}{l}\text { F } \\
\text { B }\end{array}$ & $\begin{array}{l}63 \\
16\end{array}$ & $\begin{array}{l}43 \\
28\end{array}$ & $\begin{array}{l}47 \\
24\end{array}$ & $\begin{array}{l}55 \\
\text { facilitator }\end{array}$ & No \\
\hline $\begin{array}{l}\text { An integrated care system is organised as such } \\
\text { that a team of caregivers is responsible for the } \\
\text { care of a pregnant woman. The role of each } \\
\text { professional is well-defined and each professional } \\
\text { is personally responsible for his/her own tasks }\end{array}$ & $\begin{array}{l}\text { F } \\
\text { B }\end{array}$ & $\begin{array}{l}87 \\
3\end{array}$ & $\begin{array}{l}86 \\
5\end{array}$ & $\begin{array}{l}84 \\
5\end{array}$ & $\begin{array}{l}86 \\
\text { facilitator }\end{array}$ & Yes \\
\hline \multicolumn{7}{|l|}{ Continuity of care } \\
\hline $\begin{array}{l}\text { Each client has a written birth plan expressing her } \\
\text { wishes concerning the birth (midwife-led as well } \\
\text { as obstetrician-led care) }\end{array}$ & $\begin{array}{l}\text { F } \\
\text { B }\end{array}$ & $\begin{array}{l}53 \\
14\end{array}$ & $\begin{array}{l}80 \\
1\end{array}$ & $\begin{array}{l}82 \\
0\end{array}$ & $\begin{array}{l}64 \\
\text { facilitator }\end{array}$ & No \\
\hline $\begin{array}{l}\text { All caregivers use a joint electronic client record } \\
\text { system }\end{array}$ & $\begin{array}{l}\text { F } \\
\text { B }\end{array}$ & $\begin{array}{l}97 \\
1\end{array}$ & $\begin{array}{l}99 \\
0\end{array}$ & $\begin{array}{l}100 \\
0\end{array}$ & $\begin{array}{l}98 \\
\text { facilitator }\end{array}$ & Yes \\
\hline $\begin{array}{l}\text { The management of care for all pregnant women } \\
\text { is discussed with all primary and secondary } \\
\text { caregivers in a structured manner. }\end{array}$ & $\begin{array}{l}\text { F } \\
\text { B }\end{array}$ & $\begin{array}{l}88 \\
4\end{array}$ & $\begin{array}{l}61 \\
21\end{array}$ & $\begin{array}{l}76 \\
10\end{array}$ & $\begin{array}{l}78 \\
\text { facilitator }\end{array}$ & Yes \\
\hline $\begin{array}{l}\text { Every client has a case-manager who is the first } \\
\text { point of call, even when the client is referred to } \\
\text { another professional }\end{array}$ & $\begin{array}{l}\mathbf{F} \\
\mathbf{B}\end{array}$ & $\begin{array}{l}59 \\
19\end{array}$ & $\begin{array}{l}59 \\
12\end{array}$ & $\begin{array}{l}76 \\
10\end{array}$ & $\begin{array}{l}61 \\
\text { facilitator }\end{array}$ & No \\
\hline $\begin{array}{l}\text { After referral from midwife-led to obstetrician- } \\
\text { led care, it is important to minimize the number } \\
\text { of health care professionals involved }\end{array}$ & $\begin{array}{l}\text { F } \\
\text { B }\end{array}$ & $\begin{array}{l}74 \\
6\end{array}$ & $\begin{array}{l}93 \\
2\end{array}$ & $\begin{array}{l}90 \\
5\end{array}$ & $\begin{array}{l}82 \\
\text { facilitator }\end{array}$ & Yes \\
\hline $\begin{array}{l}\text { The use of a "care pathway" will support a } \\
\text { consistent and unequivocal policy }\end{array}$ & $\begin{array}{l}\text { F } \\
\text { B }\end{array}$ & $\begin{array}{l}77 \\
3 \\
\end{array}$ & \begin{tabular}{|l|}
83 \\
5 \\
\end{tabular} & $\begin{array}{l}79 \\
3 \\
\end{array}$ & $\begin{array}{l}79 \\
\text { facilitator }\end{array}$ & Yes \\
\hline $\begin{array}{l}\text { The use of "pathways" will help to create a policy } \\
\text { that is synchronized to the needs of the client. }\end{array}$ & $\begin{array}{l}\mathbf{F} \\
\mathbf{B}\end{array}$ & $\begin{array}{l}64 \\
4\end{array}$ & $\begin{array}{l}72 \\
8\end{array}$ & $\begin{array}{l}71 \\
8\end{array}$ & $\begin{array}{l}67 \\
\text { facilitator }\end{array}$ & No \\
\hline
\end{tabular}


Perdok, H., Jans, S., Verhoeven, C., Dillen C., Batenburg, R., Mol, B.W., Schellevis, F., Jonge, An de. Opinions of professionals about integrating midwife- and obstetrician-led care in The Netherlands. Midwifery: 2016, 37(6), 9-18

Table 2 (continued)

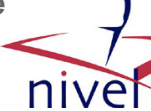

\begin{tabular}{|c|c|c|c|c|c|c|}
\hline Education & & & & & & \\
\hline $\begin{array}{l}\text { Primary care midwives should be trained to assist } \\
\text { women with a "moderate-risk" indication }\end{array}$ & $\begin{array}{l}\text { F } \\
\text { B }\end{array}$ & $\begin{array}{l}54 \\
25\end{array}$ & $\begin{array}{l}83 \\
7\end{array}$ & $\begin{array}{l}67 \\
16\end{array}$ & $\begin{array}{l}64 \\
\text { facilitator }\end{array}$ & No \\
\hline $\begin{array}{l}\text { Primary care midwives should have enough } \\
\text { practical experience to be and remain competent } \\
\text { in assisting "moderate risk" births }\end{array}$ & F & $\begin{array}{l}58 \\
18\end{array}$ & $\begin{array}{l}79 \\
4\end{array}$ & $\begin{array}{l}81 \\
5\end{array}$ & $\begin{array}{l}67 \\
\text { facilitator }\end{array}$ & No \\
\hline $\begin{array}{l}\text { Midwives are trained in such a way that they are } \\
\text { able to work in both primary and secondary care }\end{array}$ & $\begin{array}{l}\mathbf{F} \\
\mathbf{B}\end{array}$ & $\begin{array}{l}53 \\
24\end{array}$ & $\begin{array}{l}60 \\
16\end{array}$ & $\begin{array}{l}54 \\
35\end{array}$ & $\begin{array}{l}55 \\
\text { facilitator }\end{array}$ & No \\
\hline Finance & & & & & & \\
\hline $\begin{array}{l}\text { Currently financial motives exist which interfere } \\
\text { with the type of care that is given to a labouring } \\
\text { woman in midwife-led care }\end{array}$ & $\begin{array}{l}\text { F } \\
\text { B }\end{array}$ & \begin{tabular}{|l|}
3 \\
87
\end{tabular} & $\begin{array}{l}11 \\
43\end{array}$ & $\begin{array}{l}14 \\
71\end{array}$ & $\begin{array}{l}72 \\
\text { barrier }\end{array}$ & No \\
\hline $\begin{array}{l}\text { Currently financial motives exist which interfere } \\
\text { with the type of care to a woman in labour }\end{array}$ & $\begin{array}{l}\text { F } \\
\text { B }\end{array}$ & $\begin{array}{ll}5 \\
61\end{array}$ & $\begin{array}{l}2 \\
57\end{array}$ & $\begin{array}{l}11 \\
69\end{array}$ & \begin{tabular}{|l}
61 \\
barrier
\end{tabular} & No \\
\hline $\begin{array}{l}\text { Financial motives could interfere with the } \\
\text { implementation of integrated care during labour }\end{array}$ & $\begin{array}{l}\mathbf{F} \\
\mathbf{B}\end{array}$ & $\begin{array}{l}12 \\
75\end{array}$ & $\begin{array}{l}15 \\
68\end{array}$ & $\begin{array}{l}20 \\
66\end{array}$ & $\begin{array}{l}72 \\
\text { barrier }\end{array}$ & Yes \\
\hline $\begin{array}{l}\text { Professionals will be paid for the work they } \\
\text { actually do instead of a fixed sum for the total } \\
\text { care given }\end{array}$ & $\begin{array}{l}\mathbf{F} \\
\mathbf{B}\end{array}$ & $\begin{array}{l}23 \\
46\end{array}$ & $\begin{array}{l}38 \\
43\end{array}$ & $\begin{array}{l}34 \\
49\end{array}$ & $\begin{array}{l}46 \\
\text { barrier }\end{array}$ & No \\
\hline Health care professionals collectively receive an & F & 45 & 20 & 29 & 41 & No \\
\hline $\begin{array}{l}\text { integral tariff which they have to divide according } \\
\text { to tasks performed and care given }\end{array}$ & B & 31 & 56 & 51 & barrier & \\
\hline $\begin{array}{l}\text { Health care professionals will be paid } \\
\text { individually for the tasks performed and care } \\
\text { given. Funds will be available for collaborative } \\
\text { activities }\end{array}$ & $\begin{array}{l}\text { F } \\
\text { B }\end{array}$ & $\begin{array}{l}51 \\
24\end{array}$ & $\begin{array}{l}83 \\
7\end{array}$ & $\begin{array}{l}60 \\
17\end{array}$ & $\begin{array}{l}62 \\
\text { facilitator }\end{array}$ & No \\
\hline $\begin{array}{l}\text { Finances (declarations) concerning care are } \\
\text { managed by an independent organization }\end{array}$ & $\begin{array}{l}\mathbf{F} \\
\mathbf{B}\end{array}$ & $\begin{array}{l}49 \\
18\end{array}$ & $\begin{array}{l}55 \\
20\end{array}$ & $\begin{array}{l}74 \\
6\end{array}$ & $\begin{array}{l}53 \\
\text { facilitator }\end{array}$ & No \\
\hline
\end{tabular}

\section{$\mathrm{F}=$ Facilitator; $\mathrm{B}=$ Barrier}

$0=0$ bstetrician; $\mathrm{P}=$ Primary care midwife; $\mathrm{C}=$ Clinical midwife

Consensus: $>70 \%$ of all panel members and $>50 \%$ per professional group agree or disagree

Statements for which consensus was observed are reported in grey,

If more than $60 \%$ of the participants thought the statement to be (not) influential, the statement is shown in this table. 
Perdok, H., Jans, S., Verhoeven, C., Dillen C., Batenburg, R., Mol, B.W., Schellevis, F., Jonge, An de. Opinions of professionals about integrating midwife- and obstetrician-led care in The Netherlands. Midwifery: 2016, 37(6), 9-18

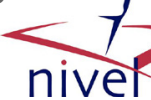

Table 3

Opinions about responsibilities of maternity health professionals in managing moderate risk indications.

\begin{tabular}{|c|c|c|c|c|c|c|}
\hline \multirow[t]{2}{*}{ Statement } & \multicolumn{4}{|c|}{$\begin{array}{l}\text { Opinion per } \\
\text { professional group } \\
(\%)\end{array}$} & \multirow[t]{2}{*}{$\begin{array}{l}\text { Total group } \\
(\%)\end{array}$} & \multirow[t]{2}{*}{ Consensus } \\
\hline & & $\mathbf{O}$ & $\overline{\mathbf{P}}$ & $\mathrm{C}$ & & \\
\hline \multicolumn{7}{|l|}{ Request for pain relief (Medical) } \\
\hline $\begin{array}{l}\text { The primary care midwife is totally } \\
\text { responsible for care, without involvement } \\
\text { of the obstetrician. When an epidural is } \\
\text { required, the clinical midwife refers the } \\
\text { woman to the anaesthetist without prior } \\
\text { consultation of the obstetrician. }\end{array}$ & $\begin{array}{l}\text { A } \\
\text { D }\end{array}$ & $\begin{array}{l}7 \\
88\end{array}$ & $\begin{array}{l}21 \\
62\end{array}$ & $\begin{array}{l}22 \\
67\end{array}$ & 77 disagree & Yes \\
\hline $\begin{array}{l}\text { The clinical midwife is totally responsible } \\
\text { for care, without involvement of the } \\
\text { obstetrician. When an epidural is required, } \\
\text { the clinical midwife refers the woman to the } \\
\text { anaesthetist without prior consultation of } \\
\text { the obstetrician. }\end{array}$ & $\begin{array}{l}\text { A } \\
\text { D }\end{array}$ & $\begin{array}{l}38 \\
50\end{array}$ & $\begin{array}{l}43 \\
42\end{array}$ & $\begin{array}{l}67 \\
26\end{array}$ & 45 disagree & No \\
\hline $\begin{array}{l}\text { The primary care midwife may provide care } \\
\text { (with or without final responsibility of care } \\
\text { by obstetrician or clinical midwife) }\end{array}$ & $\begin{array}{l}\text { A } \\
\text { D }\end{array}$ & $\begin{array}{l}23 \\
60\end{array}$ & $\begin{array}{l}66 \\
18\end{array}$ & $\begin{array}{l}37 \\
44\end{array}$ & 45 disagree & No \\
\hline $\begin{array}{l}\text { The clinical midwife may provide care (with } \\
\text { or without final responsibility of care by } \\
\text { obstetrician) }\end{array}$ & $\begin{array}{l}\text { A } \\
\mathrm{D}\end{array}$ & $\begin{array}{l}85 \\
7\end{array}$ & $\begin{array}{l}57 \\
22\end{array}$ & $\begin{array}{l}89 \\
4\end{array}$ & 76 agree & Yes \\
\hline \multicolumn{7}{|l|}{ Thick meconium stained amniotic liquor } \\
\hline $\begin{array}{l}\text { The primary care midwife is totally } \\
\text { responsible for care, without involvement } \\
\text { of the obstetrician }\end{array}$ & $\begin{array}{l}\text { A } \\
\text { D }\end{array}$ & $\begin{array}{l}11 \\
79\end{array}$ & $\begin{array}{l}30 \\
53\end{array}$ & $\begin{array}{l}37 \\
48\end{array}$ & 67 disagree & No \\
\hline $\begin{array}{l}\text { The clinical midwife is totally responsible } \\
\text { for care, without involvement of the } \\
\text { obstetrician }\end{array}$ & $\begin{array}{l}\mathrm{A} \\
\mathrm{D}\end{array}$ & $\begin{array}{l}42 \\
39\end{array}$ & $\begin{array}{l}44 \\
37\end{array}$ & $\begin{array}{l}85 \\
7\end{array}$ & 47 agree & No \\
\hline $\begin{array}{l}\text { The primary care midwife may provide care } \\
\text { (with or without final responsibility of care } \\
\text { by obstetrician or clinical midwife) }\end{array}$ & $\begin{array}{l}\text { A } \\
\text { D }\end{array}$ & $\begin{array}{l}26 \\
64\end{array}$ & $\begin{array}{l}74 \\
15\end{array}$ & $\begin{array}{l}37 \\
44\end{array}$ & 46 disagree & No \\
\hline $\begin{array}{l}\text { The clinical midwife may provide care (with } \\
\text { or without final responsibility of care by } \\
\text { obstetrician) }\end{array}$ & $\begin{array}{l}\text { A } \\
\text { D }\end{array}$ & $\begin{array}{l}85 \\
6\end{array}$ & $\begin{array}{l}53 \\
24\end{array}$ & $\begin{array}{l}78 \\
15\end{array}$ & 74 agree & Yes \\
\hline \multicolumn{7}{|l|}{ Thin meconium stained amniotic liquor } \\
\hline $\begin{array}{l}\text { The primary care midwife is totally } \\
\text { responsible for care, without involvement } \\
\text { of the obstetrician }\end{array}$ & $\begin{array}{l}\text { A } \\
\text { D }\end{array}$ & $\begin{array}{l}16 \\
73\end{array}$ & $\begin{array}{l}48 \\
38\end{array}$ & $\begin{array}{l}48 \\
37\end{array}$ & 58 disagree & No \\
\hline $\begin{array}{l}\text { The clinical midwife is totally responsible } \\
\text { for care, without involvement of the } \\
\text { obstetrician }\end{array}$ & $\begin{array}{l}\mathrm{A} \\
\mathrm{D}\end{array}$ & $\begin{array}{l}60 \\
26\end{array}$ & $\begin{array}{l}47 \\
36\end{array}$ & $\begin{array}{l}78 \\
15\end{array}$ & 58 agree & No \\
\hline $\begin{array}{l}\text { The primary care midwife may provide care } \\
\text { (with or without final responsibility of care }\end{array}$ & $\begin{array}{l}\text { A } \\
\text { D }\end{array}$ & $\begin{array}{l}31 \\
53 \\
\end{array}$ & $\begin{array}{l}82 \\
9 \\
\end{array}$ & $\begin{array}{l}56 \\
33 \\
\end{array}$ & 50 agree & No \\
\hline \multicolumn{7}{|l|}{ by obstetrician or clinical midwife) } \\
\hline $\begin{array}{l}\text { The clinical midwife may provide care (with } \\
\text { or without final responsibility of care by } \\
\text { obstetrician) }\end{array}$ & $\begin{array}{l}\text { A } \\
\text { D }\end{array}$ & $\begin{array}{l}84 \\
8\end{array}$ & $\begin{array}{l}46 \\
36\end{array}$ & $\begin{array}{l}82 \\
15\end{array}$ & 72 agree & No \\
\hline \multicolumn{7}{|l|}{ Failure to progress 1st stage } \\
\hline $\begin{array}{l}\text { The primary care midwife is totally } \\
\text { responsible for care, without involvement } \\
\text { of the obstetrician }\end{array}$ & $\begin{array}{l}\text { A } \\
\mathbf{D}\end{array}$ & $\begin{array}{l}4 \\
92\end{array}$ & $\begin{array}{l}16 \\
68\end{array}$ & $\begin{array}{l}26 \\
67\end{array}$ & 82 disagree & Yes \\
\hline $\begin{array}{l}\text { The clinical midwife is totally responsible } \\
\text { for care, without involvement of the } \\
\text { obstetrician }\end{array}$ & $\begin{array}{l}\text { A } \\
\text { D }\end{array}$ & $\begin{array}{l}30 \\
58\end{array}$ & $\begin{array}{l}34 \\
53\end{array}$ & $\begin{array}{l}63 \\
30\end{array}$ & 53 disagree & No \\
\hline $\begin{array}{l}\text { The primary care midwife may provide care } \\
\text { (with or without final responsibility of care } \\
\text { by obstetrician) }\end{array}$ & $\begin{array}{l}\text { A } \\
\mathbf{D}\end{array}$ & $\begin{array}{l}19 \\
67\end{array}$ & $\begin{array}{l}65 \\
20\end{array}$ & $\begin{array}{l}44 \\
37\end{array}$ & 49 disagree & No \\
\hline $\begin{array}{l}\text { The clinical midwife may provide care (with } \\
\text { or without final responsibility of care by } \\
\text { obstetrician) }\end{array}$ & $\begin{array}{l}\text { A } \\
\text { D }\end{array}$ & $\begin{array}{l}85 \\
7\end{array}$ & $\begin{array}{l}55 \\
24\end{array}$ & $\begin{array}{l}85 \\
7\end{array}$ & 76 agree & Yes \\
\hline
\end{tabular}


Perdok, H., Jans, S., Verhoeven, C., Dillen C., Batenburg, R., Mol, B.W., Schellevis, F., Jonge, An de. Opinions of professionals about integrating midwife- and obstetrician-led care in The Netherlands. Midwifery: 2016, 37(6), 9-18

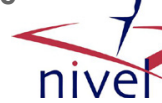

Table 3 (continued)

\begin{tabular}{|l|l|l|l|l|l|l|l|}
\hline Prolonged rupture of membranes & A & 12 & 30 & 35 & 64 disagree & No \\
\hline $\begin{array}{l}\text { The primary care midwife is totally } \\
\text { responsible for care, without involvement } \\
\text { of the obstetrician }\end{array}$ & D & 77 & 45 & 54 & & No \\
\hline $\begin{array}{l}\text { The clinical midwife is totally responsible } \\
\text { for care, without involvement of the }\end{array}$ & A & 45 & 38 & 69 & 45 agree & \\
obstetrician & D & 44 & 43 & 23 & & No \\
\hline $\begin{array}{l}\text { The primary care midwife may provide care } \\
\text { (with or without final responsibility of care } \\
\text { by obstetrician) }\end{array}$ & D & 32 & 58 & 71 & 54 & 47 agree & 23 \\
\hline $\begin{array}{l}\text { The clinical midwife may provide care (with } \\
\text { or without final responsibility of care by } \\
\text { obstetrician) }\end{array}$ & A & D & 48 & 65 & 92 & 81 agree & Yes \\
\hline
\end{tabular}

$\mathrm{A}=$ Agree; $\mathrm{D}=$ Disagree

$\mathrm{O}=$ Obstetrician; $\mathrm{P}=$ Primary care midwife; $\mathrm{C}=$ Clinical midwife

Consensus: $>70 \%$ of all panel members and $>50 \%$ per professional group agree or disagree

Statements for which consensus was observed are reported in grey. 